\title{
Managing information in road traffic: best practices
}

\author{
Karolina Lubieniecka-Kocon ${ }^{1,}$ \\ ${ }^{1}$ Department of rail transport, WSB University, Cieplaka 1C, 41-300 Dąbrowa Górnicza, Poland
}

\begin{abstract}
When considering road safety, applying the appropriate infrastructure and methods of using it occurs. Thus, it seem important to ask the question not only how to gather the information, but also, how to manage it. Possessing information does not equal using it, therefore, there have been analysed the methods used to gather and manage the information concerning the traffic incidents and the warnings about the conditions that could possibly increase the probability of the occurrence of such happenings. The comparative analysis and short overview have been performed for the requirements of hereby article so as to address the abovementioned issues. Those have led to creating short portfolio of most interesting solutions that may be applicable to the systems monitoring the safety in high density road infrastructure. The conclusions try to answer the questions which highlight the correlation that is perceived between the effective use of the chosen method and the information management approach, as well as the correlation between the scope of the investment performed and the effectiveness of the launched solution. It may happen the latter may not be directly linked with the former, although it cannot be denied that many of the systems are usually a bit expensive.
\end{abstract}

\section{Introduction}

When considering the issue of road safety, the notion of applying the appropriate infrastructure and methods of using it occurs. Thus, identifying the goals of the hereby text, it seem important to ask the question not only how to gather the information concerning the road safety, but also, how to manage and use it.

In the struggle to address the needs of all road users for greater safety, various tools are applied. One of the popular approaches is the idea to monitor traffic strictly and to react on the upcoming events, if reacting in advance on some signals concerning the disruptions is not possible. However, such approach require answering two crucial aspects: the first one, how to gather the information concerning the traffic, and the second issue, how to manage and transfer the information acquired. Therefore, it appears to be an interesting idea to analyse the methods used to gather and manage the information concerning the traffic incidents and the warnings, such as traffic density, road condition, road character or changing weather conditions. In hereby article the following aspects of the system have

\footnotetext{
* Corresponding author: kkocon@wsb.edu.pl
} 
been taken under the consideration: incident management, demand management, monitoring system, driver support, and public transport management.

There are various approaches applied, depending on the local transport policy, local, national or international (e.g. European) political guidelines and the will to address those. There is also the issue of already existing infrastructure and the possibility to use it, change it or renovate it. Last but not least, there is the notion of stakeholders wishing to be addressed as transport infrastructure users. From the wide variety of solutions and polices trying to address the abovementioned needs, three options have been chosen as practices worth considering: from Germany, Finland and Australia. The solutions applied in Poland have also been described.

The comparative analysis and short overview have been performed for the requirements of hereby article so as to address the abovementioned issues.

The following questions ought to be asked:

- How is the information gathered?

- How is it managed?

- What is it managed for?

- What is the result of traffic information management?

Answering to such questions may help to compare and contrast various approaches towards traffic information management. Then, the systems used in the described countries may be compared and if found interesting, applied at home country.

\section{Solutions overview}

As mentioned above, the solutions from three countries have been taken into consideration: from Germany, where as early as in 2006 there was presented cohesive solution for data collecting, transferring and managing, from Finland, where the approach putting the traffic user was placed in the centre of the authorities efforts to facilitate the traffic and from Australia, where the issue of unexpected causes of delays in transport were considered.

\subsection{Solutions from Germany}

The approach and solutions, provided by Siemens in Munich and offered to several cities in Germany are the oldest from the analyzed for the requirements of the hereby article. The approach was presented in 2006 during the seminar on Intelligent Transport Systems in Road Network Operations in Malaysia [1], however, despite the time span, it still seems very coherent and worth analyzing.

German approach draws attention through its well designed form and clearly defined tools. Siemens offered the holistic approach towards the system of information management, which would include traffic infrastructure network, three level system that would control it, and the idea to merge independent traffic systems already existing in the cities into one network of data collection [1]. The solutions suggests creating one platform, collecting data form radar, above ground detectors, cars, operator messages, highway systems or traffic control center, weather data detectors and camera systems; such platform would create the system traffic management capability [1]. The information is shared with the traffic participants via mobile, radio, web portals, or in-car navigation systems. Thus, the systems offers fast and coherent solution to collect and transfer information on all potential situations happening in road traffic, as presented below: 


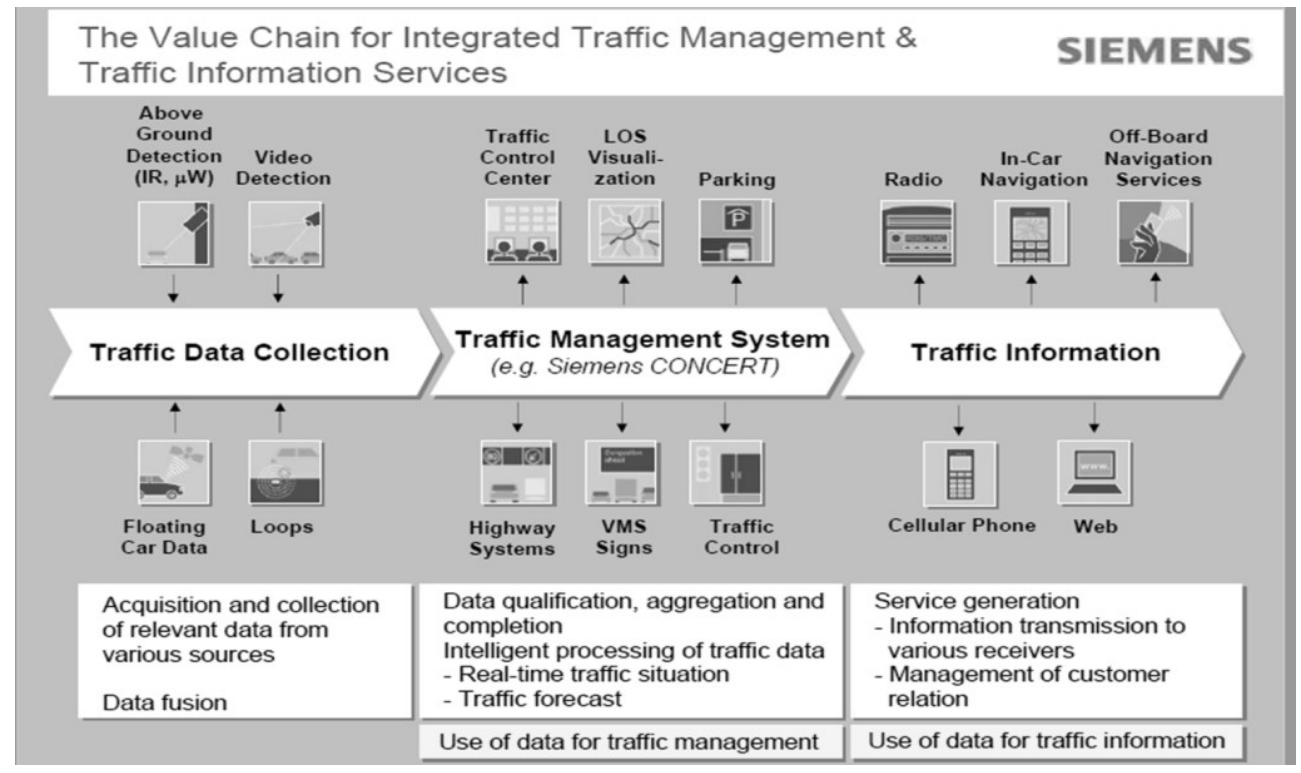

Fig. 1. Co-operation Traffic Management and Traffic Information [1].

The system presented by Siemens offered the solution in public-private partnership. The solution was launched in Bavaria, Berlin, and most recently (the program designed for 2004-2017) in North Rhine Westphalia [1]. The last one, called RuhrPilot, covered the area of highest population density in Germany and is still being developed. The idea, seem to offer really cohesive approach towards information management in road transport and traffic. Four companies signed PPP contract with local authorities to provide the system enabling better use of traffic management [2]. The system, consisting of already described elements, provides updated information on traffic, allowing to manage and to adjust to it.

\subsection{Solutions from Finland}

In 2010 in Finland there was launched the national strategy for intelligent transport [3]. The program focused on managing traffic information, aiming on predictability and reliability of travel as well as prevention of the incidents together with minimizing their effects [3]. Finnish solutions for information management assumed that it is possible to receive shortterm predicted status of the traffic system, which in turn allows to seek for solutions predicting potential problems, not only addressing already existing ones [3].

The system offers updated information sent to road users, allowing to be informed before the travel and during it. The information that was sent considered the following issues: weather, road condition, road maintenance, traffic incidents, traffic situation and if necessary, alternative modes of travel [3].

Generally speaking, the elements used to create the management system are similar, if not the same, as in German approach. However, what distinguishes Finnish solution, is the approach towards the identified problems and offered solutions. What seems significant is that despite the fact of completely different population density in Germany and Finland, suggested solutions seem to fit the traffic management problems of both of the countries. Table number 1 presents the set of goals the program defined, together with two means of reaching it. It seems interesting to see the majority of the fist-choice solutions are automatic, handled with no human factor, whereas the second-choice solutions are humanprovided. 
Table 1. Most important goals and means of the Finnish national program of traffic management [3].

\begin{tabular}{|c|c|c|}
\hline Desired effect & $1^{\text {st }}$ means & $2^{\text {nd }}$ means \\
\hline $\begin{array}{l}\text { Reduced number of deaths and } \\
\text { injuries }\end{array}$ & Automatic monitoring & Variable traffic control \\
\hline Basic safety & Safety notifications & Services at rest stops \\
\hline Compliance with traffic regulations & Automatic monitoring & Variable traffic control \\
\hline Predictability & Incident management & Safety notifications \\
\hline Reliability & Incident management & Road use charges \\
\hline Elimination of incidents & Variable traffic control & Backup routes \\
\hline $\begin{array}{l}\text { Attractiveness of pedestrian and } \\
\text { bicycle traffic and public transport }\end{array}$ & Road use charges & Multimodal route service \\
\hline $\begin{array}{c}\text { Constraining growth in passenger car } \\
\text { traffic }\end{array}$ & Road use charges & $\begin{array}{c}\text { Multimodal information } \\
\text { service }\end{array}$ \\
\hline Combating climate change & Road use charges & Incident management \\
\hline Travel by the elderly & Driver support & Information services \\
\hline
\end{tabular}

It seem important to notice that the goals set for traffic management are common for any kind of traffic management. However, the information management used as a tool here is focused on notifications and informing rather than on gathering. Passing the information appears to be the most important element of the information management approach in the given example. Perhaps it is due to the fact that the program was announced with its focus on traffic safety and effectiveness with which information is to reach the addressees [4]. Due to the vastness of the region and the challenges of the environment, such goal truly seems to be the most challenging.

\subsection{Solutions from Australia}

Traffic Management in New South Wales, Australia, focuses on optimizing road space allocation and traffic movement so that to manage such issues, as information improving road safety, public transport information, touristic movement, congestion problems, and delays caused by planned and unplanned situation [5].

What seems especially important is the service of incident management. The authorities offer special tool for communication with the stakeholders interested in receiving the most updated information on the condition of road network. The "Fact sheet" includes information provided by the state road authorities, national services and local councils. The document is created and read basing on four steps [5]: selecting the route, identifying potential diversion routes, developing incident response plan and stakeholder consultation, and distributing of the incident response plan and sending information to the end users.

What seems worth highlighting is the exceptional role of the stakeholders in the process. Thus, information management in such case focuses on maintaining truly two-side communication in difficult situations. That is the element which sometimes seems to be forgotten in traditional approach, where the traffic users may be perceived as the information donors, but not the management creators.

It also needs to be highlighted that emergency situations are not dealt with using the fact sheet. Those are designed in OneRMS Safety Management System [6], which identifies challenges in road safety management system and helps to build the path to deal with them. The document focuses on risk management and on eliminating or ratherminimizing the hazards the road users face [6]. Its main targets are shown on its introductory site, presented below: 


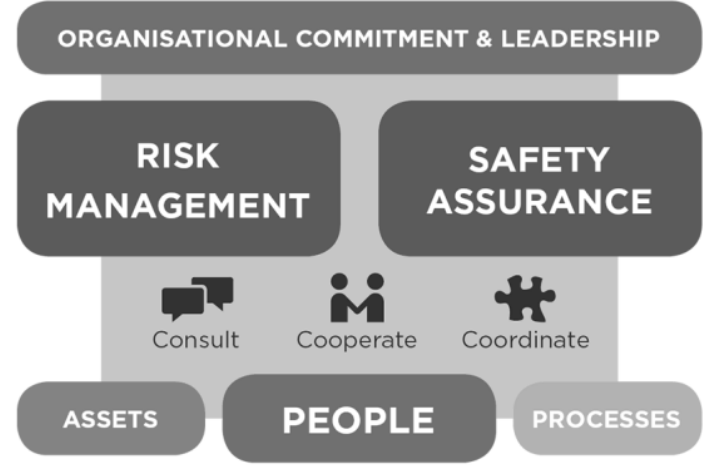

Fig. 2. OneRMS Safety Management System [6].

The cooperation with another services providing tools for managing emergency situations and the channels of communication are well designed and their importance - highlighted. It seems mutual understanding and being up to date with the solutions and current situation is the most crucial aspect of the approach of the Australian authorities.

\subsection{Solutions launched in Poland}

Poland has had its own vision on traffic information management. One of the most important and most recent steps in road traffic management is the tender announcement of GDDKiA (General Directorate for National Roads and Motorways). The idea of the Directorate is to create the national system of road traffic management, thus concentrating the efforts to unify the smart solutions implemented in various cities and municipalities at local level. In January 2018 there was signed the contract to realize the project and the basis of the system [7], and in October 2018 there appeared first information on the tender preparation for four regional pilot projects for the designed system [8]. It is important to highlight the road management system designed in Poland is to focus on the roads included into the TEN-T program [8]. The first stage of the project is presented below:

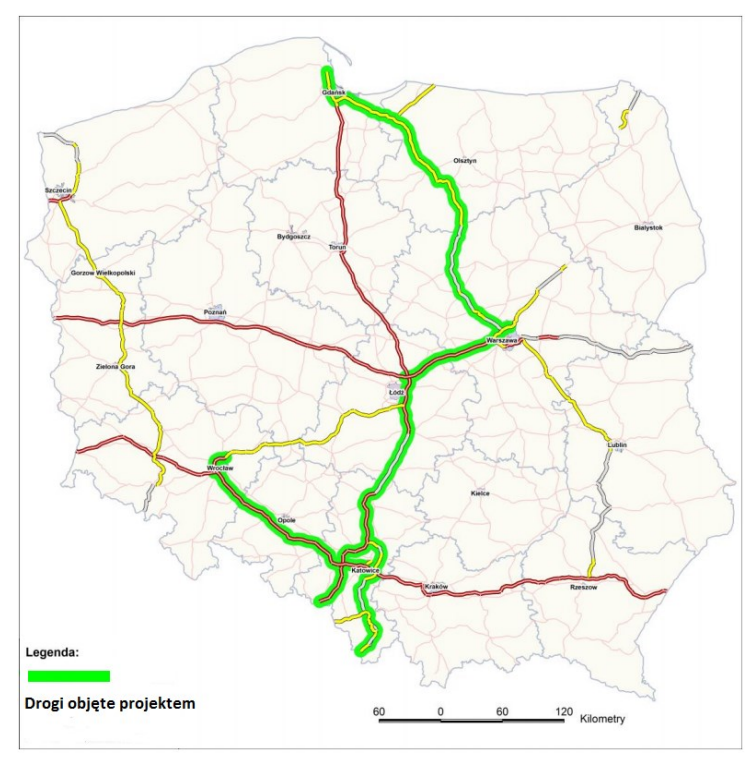

Fig. 1 First stage of road management system on TEN-T roads in Poland [9]. 
The system is to support the drivers providing the information on road difficulties, current traffic conditions, travel time and ring roads; it will also help managing traffic on overcrowded roads, facilitate emergency actions and improve road maintenance. The drivers are also to be informed about speed limit and available parking places [10]. The system is to be implemented by 2023, and its total cost is 2 billion PLN [10].

\subsection{Virtual practices}

Another practices that seem worth noticing are not necessarily used in one country as a fully designed approach towards information management. They rather seem to be a kind of a set of tools that may offer some help so as to manage not only information flow, but also, the reaction on passing certain types of messages. Testing the way stakeholders may react in emergency situation when using road transport is crucial; such practicing may take place in real road conditions, but as Dethridge and Quinn point out, they may happen in virtual world [11]. Desired reaction may be practiced in such place as Second Life; complex, three-dimensional graphic environment that may perhaps be more attractive to those who would not consider taking part in standard- designed drill themselves.

This procedure is especially important if the authorities would like the community members cooperate in the situation when the information on road emergency reaches them. Granot [12], but also Kapucu, Arslan and Demiroz [13] highlight the importance of cooperation not only during normal life situations, but also in emergency calls; the tool helping people to build common response in difficult situation they may face when on road may be the priceless source of experiencing the difficulty in "laboratory" conditions.

\section{Conclusion}

Managing information considering road traffic is of demanding nature. Traffic is extremely complex system and it seems to be almost impossible to manage it with no problems. The element which seems to be crucial for the system to function clearly is managing information. It concerns everyday situations, informing the authorities about them and sharing this knowledge with the traffic participants. What is more, it also means trying to prevent, and if necessary, to deal with emergency situations of diverse nature. Dealing with the latter also means cooperating with traffic participants when solving the problem.

In such case, one needs to remember about two equally important parts of the system functioning. One of the key elements is the system itself; nevertheless, one cannot forget about the final users of the system; Cornes reminds the shortcomings of the approach that would base the effectiveness on the system only, reminding that the natural wish to keep the costs of programming low may affect the willingness to use the designed tools: "Screens are designed to minimize the costs of programming rather than to match manual procedures" [14]. If the system is designed to be inexpensive, it is to be focused on its automatic use rather than user-friendly built.

Another issue, equally crucial, is the human factor. The way the management systems are read and used, the will traffic participant (do not) show when faced with the road problem, innovation understood in terms of a user friendliness, those are often forgotten, yet deciding elements of successful information and traffic management. Prevention in information management should include the same factors as risk management; Lee-Mortimer reminds that risks "need to be managed (...) by identifying them, assessing their likelihood and possible impact and preparing an overall action plan to deal with them" [15]. Is seems processing and managing information should take the same route, requiring careful planning of the paths used to 
share the message and the way it is designed. One more aspect should not be forgotten: the need to learn from the mistakes; as Subramaniam, Ali, and Shamsudin wrote, it seems to be a good idea to study the sources of the type of emergency response so as to be able to properly address them [16]. Such approach ought to be used not only in emergency situation, but also when designing other elements of information content in road traffic.

When considering different approach towards information management in road traffic, even when reviewing just a few complex solutions, what attracts attention is various impact that solution creators attribute to various aspects of such kind of management. There are approaches that focus on gathering information and on processing it by traffic control units, regardless of what department. Such solutions seems really effective, especially when the traffic participants accept their passive role and agree simply to follow the orders. However, one cannot fail to notice that such role relieves participants from any responsibility for the traffic situation itself. If one is but a passive user, one cannot be expected to do more than just make some space for more active actors of the situation, whatever its nature. That may cause some problems in cases where safety of the road traffic depends more on participants themselves, e.g. due to the distance traffic controllers need to cover to deal with any of the aspects that would take place on the road.

In solutions that shift responsibility to the participants side as well, it is clearly visible that it needs to be merged with the possibility to participate in traffic management more actively; in solutions adopted in Finland and Australia it is clearly visible; not only are the road traffic participants expected to read and learn passed information, but they are welcomed as information sources, information managers and opinion makers, judging proposed means and suggesting alternative paths. Such approach may be quite difficult to manage, especially from the perspective of time management, as well from the perspective of investment costs at the stage of building the system of information managing. However, it appears to be truly effective and seem to confirm the rule that spending on effective system would be returned in lower costs of using or adapting it in the future.

It is to be hoped such approach will be found attractive in Poland; as the trend for sharing both the information, and the responsibility for one's action appears to be attractive for agile people; it should be considered when building information management system in contemporary traffic management systems, both for current and future use.

\section{References}

1. H.-J. Schade, Co-operation Traffic Management and Traffic Information, in: Int. Semin. Intell. Transp. Syst. Road Netw. Oper., pp. 1-21 (Kuala Lumpur, Malaysia, 2006)

2. F. Offermann, W. Reints, M. Ortgiese, Projekt Ruhr. Ruhrpilot traffic management regional mobility network in Germany's highly urbanized Ruhr area (2007)

3. Strategies of the Finnish Transport Agency, Road Traffic Management Strategy. Accessed on 8th April 2018, (2010)

4. Finnish Transport Agency. Available at: www.liikennevirasto.fi. Accessed: 8th April 2018, (2018)

5. Transport Roads \& Maritime Services. Available at: www.rms.nsw.gov.au. Accessed: 8th April 2018, (2018)

6. OneRMS Safety Management System Manual. Available at: http://www.rms.nsw.gov.au/safety/work-health-safety/documents/onerms-smsmanual.pdf. Accessed: 8th April 2018, (2018) 
7. GDDKiA press release on contract to design the traffic management system. Available at: https://www.gddkia.gov.pl/pl/a/28285/Kolejny-etap-wdrazania-KSZRJest-umowa-na-zaprojektowanie-i-nadzor-powstajacego-systemu. Accessed on 10th October 2018, (2018)

8. GDDKiA press release on designing pilot projects. Available at: https://www.gddkia.gov.pl/pl/a/30940/Krajowy-System-Zarzadzania-Ruchem-

Ruszaja-przetargi-na-regionalne-projekty-wdrozeniowe. Accessed on 10th October 2018, (2018)

9. GDDKiA press release on first stage of road management program. Available at: https://www.gddkia.gov.pl/pl/a/24079/Krajowy-System-Zarzadzania-RuchemDrogowym-na-sieci-TEN-T-etap-I. Accessed on 10th October 2018, (2018)

10. P. Wójtowicz, There comes the revolution on Polish roads. Available at: https://inzynieria.com/wpis-branzy/wiadomosci/5/53638,nadchodzi-rewolucja-napolskich-drogach. Accessed on 20th September 2018 (2018)

11. L. Dethridge, B. Quinn, Realtime emergency communication in virtual worlds, Int. J. Disaster Resil. Built Environ. 7 pp. 26-39 (2016). doi:10.1108/IJDRBE-08-2013-0032

12. H. Granot, Emergency inter-organizational relationships, Disaster Prev. Manag. An Int. J. 6 pp. 305-310 (1997). doi:10.1108/09653569710193736

13. N. Kapucu, T. Arslan, F. Demiroz, Collaborative emergency management and national emergency management network, Disaster Prev. Manag. An Int. J. 19 pp. 452-468 (2010). doi:10.1108/09653561011070376

14. R. Cornes, Managing Information Technology, Rec. Manag. J. 1 pp. 131-133 (1989). doi:10.1108/eb027031

15. A. Lee-Mortimer, Managing Information, TQM Mag. 3 pp. 09544789110032232 (1991). doi:10.1108/09544789110032232

16. C. Subramaniam, H. Ali, F. Mohd Shamsudin, Understanding the antecedents of emergency response: a proposed framework, Disaster Prev. Manag. An Int. J. 19 pp. 571-581 (2010). doi:10.1108/09653561011091904 